Д.М. Натаров ${ }^{1}$, А.О. Натарова ${ }^{2}$, М.Г. Кокодій ${ }^{3,4}$

${ }^{1}$ Інститут радіофізики та електроніки ім. О.Я. Усикова НАН Украӥни, Харків

${ }^{2}$ Харківський національний університет Повітряних Сил ім. І. Кожедуба, Харків

${ }^{3}$ Харківський національний університет ім. В.Н. Каразіна, Харків

${ }^{4}$ Національний фармацевтичний університет, Харків

\title{
ФОКУСУВАННЯ ЕЛЕКТРОМАГНІТНИХ ХВИЛЬ ДИСКРЕТНИМ ПАРАБОЛІЧНИМ РЕФЛЕКТОРОМ ІЗ ДІЕЛЕКТРИЧНИХ НИТОК
}

Розглянуто проблему розсіяння пласких хвиль дискретним параболічним рефлектором (ДПР), виготовленим з рівновіддалено розташованих кремнієвих ниток. Досліджено фокусуючу здатність таких відбивачів як у випадку E-, так і Н-поляризації. Для моделювання иієї задачі ми використовуємо метод часткового розділення змінних разом з регуляризацією, щьо приводить до матричного рівняння Фредгольма другого роду для коефіцієнтів розкладання функиії поля. Цей факт гарантує збіжність розв'язку та прогнозованої точності наших розрахунків. Ми чисельно вивчаємо відбиваючі характеристики ДПР та їхню фокусуючу здатність разом з картинами ближнього поля та значеннями функції поля у зоні фокусування.

Ключові слова: циліндр, дискретний параболічний рефлектор, фокусування, ближнє поле, відбивна здатність.

\section{Вступ}

Постановка проблеми. Параболічні відбивачі - найпопулярніші і широко використовувані відбивачі для фокусування електромагнітних хвиль [1]. Разом із традиційними суцільними відбивачами в сучасних антенах часто використовуються відбивачі 3 сітчастих та гнучких матеріалів [2-4].

Ідея використання сукупності дротів замість цілісних відбивачів в антенній техніці не $\epsilon$ абсолютно новою, і в [5-7] були спроби змоделювати такі відбивачі.

У роботі [8] досліджувалися ДПР, виготовлені iз срібних нанониток у видимому діапазоні довжин хвиль. Тоді було показано, що ефект періодичності, який призводить до сильного відбиття падаючої хвилі для лінійних решіток [9], руйнується через кривизну параболи і не впливає на відбиваючі та фокусуючі характеристики. Тільки збудження плазмонів на срібних нитках [9-11] трохи збільшує фокусування такими ДПР.

Метою цієї роботи є дослідження двовимірних ДПР, виготовлених з ниток з круглим перерізом.

У даній роботі, на відміну від роботи [8], ми розглядаємо не металеві, а діелектричні нитки, наприклад, кремнієві 3 діелектричною проникністю $\varepsilon=12$, і нехтуємо дисперсією та втратами в матеріалі. Тому можна дослідити проблему в широкому діапазоні значень відносної частоти $k a$.

Геометрія перерізу ДПР схематично показана на рис. 1.

Ми моделюємо ДПР як кінцеву сукупність $M$ паралельних однакових ниток, центри яких симетрично розташовані на параболічній кривій.
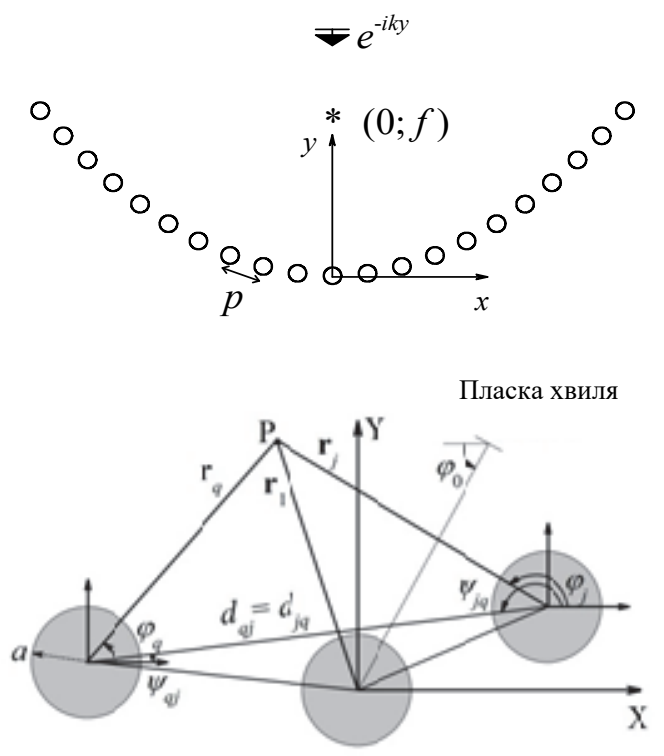

Рис. 1. Геометрія перерізу ДПР.

Джерело: розроблено авторами.

Відстань між сусідніми нитками $p$. Розглядаються нитки як нескінченні круглі циліндри, кожен 3 яких має радіус $a$ та відносну діелектричну проникність $\varepsilon$. Центральна нитка збігається $з$ вершиною параболи, яка знаходиться в початку координат, тому число $M$ непарне. Фокус параболи знаходиться в точці $(0 ; f)$, і парабола визначається рівнянням: 
$\bar{y}=a \bar{x}^{2} / 4 f$, де $\bar{y}=y a, \bar{x}=x a$. Значення апертури

$D$ параболи - це відстань між центрами крайніх ниток.

Як показано на рис. 1, ДПР висвітлюється плоскою хвилею, що падає вздовж осі $y$.

Потрібно знайти скалярну функцію, яка $\epsilon z$ компонентою розсіяного поля. Вона повинна задовольняти рівнянню Гельмгольца 3 відповідними хвилевими числами всередині і зовні ниток, умовами безперервності тангенціальних компонент поля, умові випромінювання на нескінченності та умовою локальної обмеженості потужності поля. Повнохвильовий чисельний розв'язок проблеми можна отримати аналогічно [9; 11], розклавши функції поля по кутових експонентах в локальних полярних координатах, використовуючи теореми додавання для циліндричних функцій та застосовуючи граничні умови на поверхні кожної з $M$ ниток. Це призводить до блочного матричного рівняння $M \times M$, де кожен блок нескінченний. Важливим моментом $є$ масштабування невідомих коефіцієнтів та отримання матричного рівняння Фредгольма другого роду [9; 11]. У цьому випадку збіжність розв'язку такого рівняння після усічення кожного блоку до кінцевого порядку $N$ до точного гарантується теоремами Фредгольма.

\section{ЧИСЕЛЬНІ РЕЗУЛЬТАТИ}

В представленому аналізі ми досліджуємо властивості розсіювання та фокусування ДПР з 51 кремнієвої нитки з різним співвідношенням $p / a$ і фіксованими $f / D=0.25$, як для випадків Е-, так і для Н-поляризації. Оскільки, як відомо з аналізу звичайних суцільних відбивачів [12-13], оптимальні параметри мають такі, для яких фокусна відстань становить чверть апертури. Отже, для фіксованого $p / a$, ми вибираємо оптимальну конфігурацію ДПР 3 $f / D=0.25$.

Властивості розсіювання таких ДПР можна охарактеризувати повним перерізом розсіювання (ППР) на одну нитку та відбивною здатністю на один період. Їх можна обчислити за такими рівняннями:

$$
\begin{gathered}
\sigma_{s}=\frac{2}{\pi M k a} \int_{0}^{2 \pi}|\Phi(\varphi)|^{2} d \varphi \\
R=\frac{2}{\pi M k p} \int_{0}^{\pi}|\Phi(\varphi)|^{2} d \varphi,
\end{gathered}
$$

де $\Phi(\varphi)$ - діаграма спрямованості випромінювання в дальній зоні;

$k$ - хвильове число вільного простору:

$$
\Phi(\varphi)=\sum_{n=-\infty}^{\infty}(-i)^{n} \xi_{n}(\varphi) e^{i n \varphi}
$$

$$
\xi_{n}(\varphi)=\sum_{q=1}^{M} z_{n}^{(q)} e^{-i k s_{q} \cos \left(\zeta_{q}-\varphi\right)},
$$

де $z_{n}^{(q)}-$ коефіцієнти розкладання функції розсіяного поля, пов'язані з $q$-ю ниткою;

$s_{q}$ та $\xi_{q}$ - відстань та кут між центрами глобальної системи координат та системою координат $q$-ї нитки відповідно.

У наших розрахунках у широкому діапазоні частот було важливо навести точні результати. Тому слід мати на увазі, що для великого $k a$ необхідно брати більший порядок усічення $N$ кожного блоку матричного рівняння для невідомих коефіцієнтів функції поля.

Ми використовуємо емпіричне правило $N=k a+5$, що дає точність у три знаки.

На рис. 2 представлені частотні залежності нормованого ППР для ДПР з $p / a=3,5$ і 8 для обох випадків поляризації в діапазоні $k a$ від 0,1 до 10 . Це означає, що у випадку $p / a=3$ нитки розташовані близько одна до одної, і збільшення цього коефіцієнта робить ДПР більш розрідженим. Найцікавіше це збільшене розсіяння ДПР складеними з ниток, діаметр яких менший за довжину хвилі, тобто у випадку, коли $k a<3.14$.
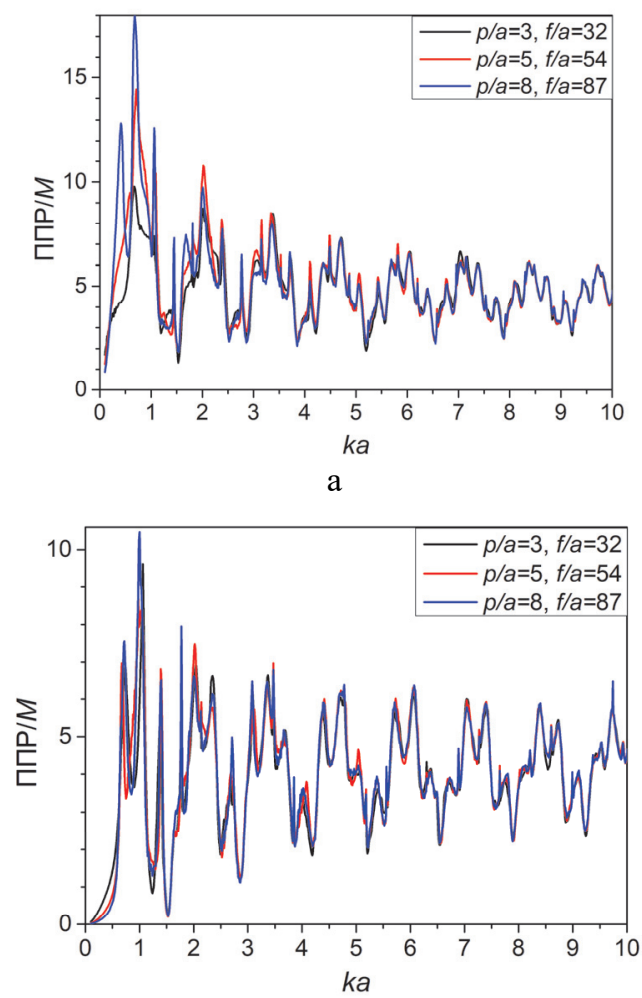

6

Рис. 2. Частотні залежності нормованого ППР для кількох ДПР із співвідношенням $p / a 3,5$ та 8: a - для випадків Е-поляризації; б - Н-поляризації Джерело: розроблено авторами. 
Дійсно, найвищі значення ППР спостерігаються в першому або другому резонансах. Така ж поведінка спостерігається у частотних залежностях нормованого коефіцієнту відбиття, які представлені на рис. 3 для тих самих ДПР. Коефіцієнт відбиття $є$ кращою характеристикою відбивних та фокусуючих характеристик ДПР, ніж ППР. Можна помітити, що резонансні частоти коефіцієнту відбиття дещо відрізняються від резонансних частот ППР. Наприклад, перший резонанс ППР для ДПР з $p / a=3$ знаходиться в Н-поляризації, для ДПР $3 \quad p / a=5$ при $k a=0.71$, для ДПР $з p / a=8$ при $k a=0.67$, а перший резонанс коефіцієнту відбиття для таких ДПР становить $k a=0.79,0,69$ та 0,74 відповідно.

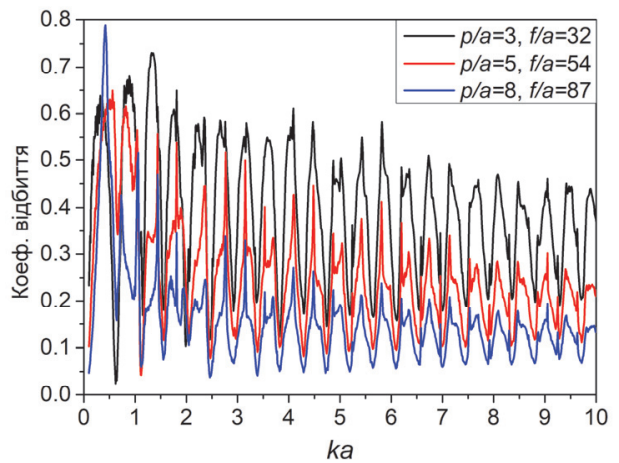

a

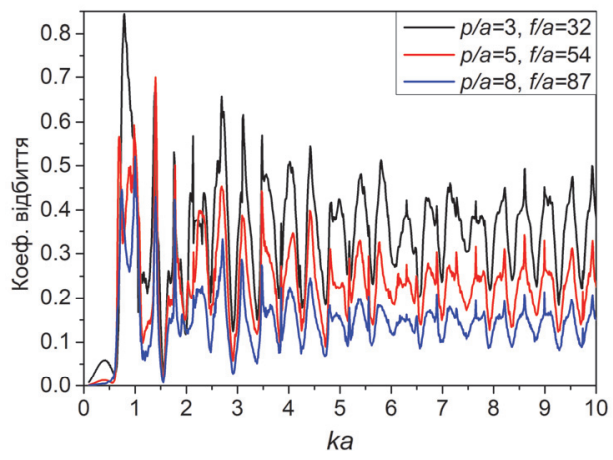

б

Рис. 3. Частотні залежності нормованого коефіцієнту відбиття для тих самих ДПР, що і на рис. 2:

a - для випадків Е-поляризації; б - та Н-поляризації

Джерело: розроблено авторами.

Ми вибрали оптично щільний матеріал ниток, оскільки такі матеріали забезпечують краще відбиття падаючих хвиль.

Для демонстрації цього на рис. 4 представлений нормований коефіцієнт відбиття як функція $k a$ для ДПР $3 p / a=5$, але 3 ниток $3 \varepsilon=12$ і 4 (це відповідає, наприклад, діоксиду кремнію). Можна помітити, що коефіцієнт відбиття ДПР 3 оптично щільніших дротів, в середньому приблизно в 1,5 рази вищий.

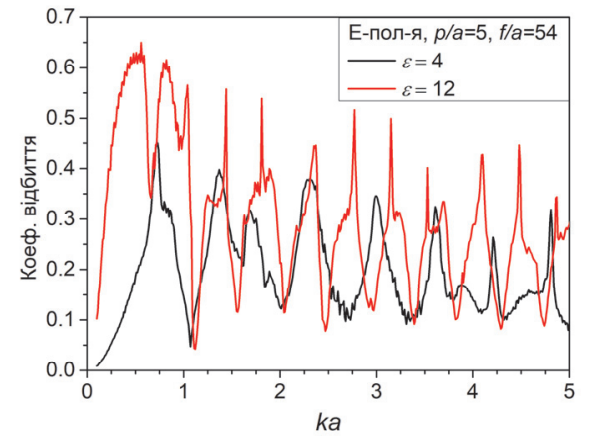

Рис. 4. Те саме, що і на рис. 3 для ДПР $з$ p/a $=5$, але зробленого з ниток з різною діелектричною проникністю.

Джерело: розроблено авторами.

На рис. 5 представлені частотні залежності максимального абсолютного значення функції поля $\mathrm{E}$ та Н (для випадків Е- та Н-поляризації відповідно) у фокальній плямі ДПР з параметрами, як на рис. 2-3.
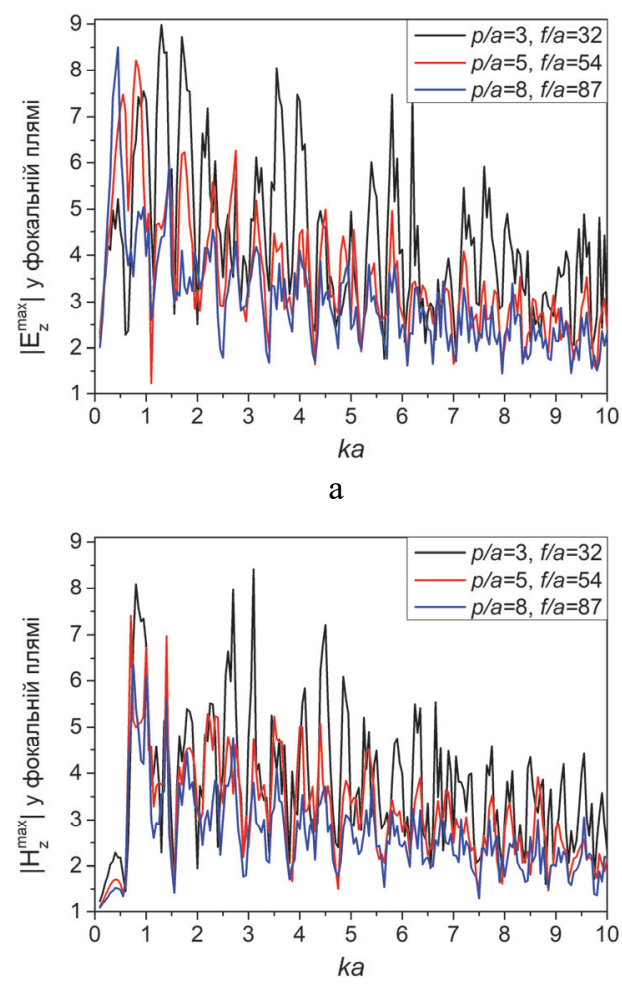

б

Рис. 5. Частотні залежності максимумів поля в фокальній плямі $(x=0 ; f-\lambda / 2<y<f+\lambda / 2)$ для тих самих ДПР, що і на рис. 2 та 3 : a - для випадків Е-поляризації; б - Н-поляризації.

Джерело: розроблено авторами.

Фокальною плямою ми вважали діапазон точок $(0, f \pm \lambda / 2)$. Ця величина характеризує здатність ДПР фокусувати електромагнітні хвилі. Як і очікувалось, резонансні частоти на графіках частотних залежностей максимума поля у фокусі збігаються 3 резонансними частотами коефіцієнту відбиття для відповідних ДПР. Слід також зауважити, що інтуї- 
тивне правило, згідно з яким щільніші ДПР відбивають і фокусують хвилі краще, ніж розріджені, в основному є правильним у всьому діапазоні, однак не $\epsilon$ правильним, якщо $k a<1$. На рис. 6 представлені дві картини амплітуди ближнього поля в перших резонансах з рис. 3, б (випадок Н-поляризації) для ДПР $з p / a=5$ на частоті $k a=0.69$ (рис. 6, а) та $p / a=8$ на частоті $k a=0.74$ (рис. 6,6 ).

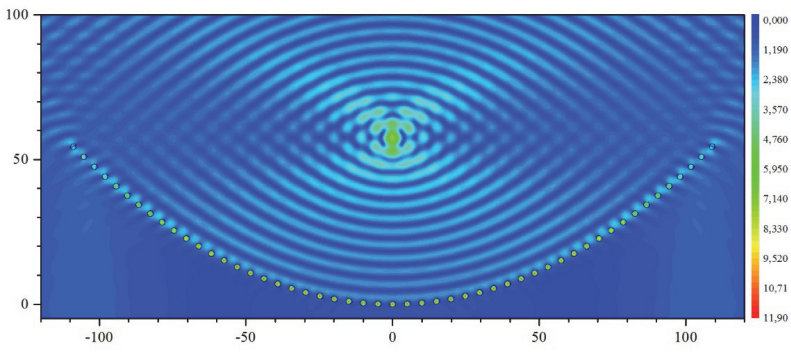

a

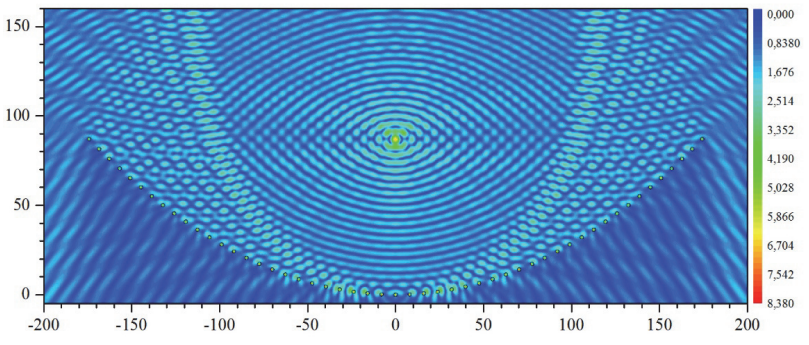

6

Рис. 6. Картини ближнього поля у перших резонансах на частотних залежностях коефіцієнту відбиття $з$ рис. $3 б$ для ДПР: $\mathrm{a}-3 \mathrm{p} / \mathrm{a}=5$ at $k a=0.69$; б-i $p / a=8$ at $k a=0.74$ (б). Джерело: розроблено авторами.
Границі ниток на картинах поля позначені чорними лініями. Нитки мають одиничні радіуси, тому розмірність ближнього поля становить $a$.

На обох зразках ближнього поля, які представлені на рис. 6, можна побачити яскраві максимуми поля всередині центральних ниток, що підтверджує припущення, що це резонанс на моді $H_{01}$ та у фокальній плямі.

Цікаво, що для ДПР з $p / a=5$ максимуми амплітуди поля в нитках вищі, ніж у його фокусі. Для ДПР $з p / a=8$ значення амплітуди поля в максимумах майже рівні між собою.

\section{Висновки}

В статті представлено електродинамічне моделювання розсіяння плоских хвиль на ДПР, зроблених зі скінченної кількості діелектричних ниток. Використана модель базується на ефективному математичному методі, і наші результати $є$ точними 3 передбачуваною похибкою.

Досліджено ДПР з ниток з високим коефіцієнтом заломлення (кремній), які разом з оптимальним співвідношенням фокусної відстані до апертури $(0,25)$ забезпечили кращу фокусуючу здібність. Продемонстровано залежності ППР, коефіцієнту відбиття, максимума амплітуди поля у фокусі досліджуваних ДПР і показано, що більш щільні ДПР, виготовлені з субхвильових ниток (нижче співвідношення $p / a$ ) відбивають та фокусують не краще, ніж розріджені ДПР.

Крім того, ми продемонстрували, що ДПР з субхвильових ниток мають найкращі відбивні та фокусуючі здібності.

\section{Список літератури}

1. Stutzman W. L., Thiele G. A. Antenna theory and design, 3rd Ed., Hoboken : John Wiley \& Sons, 2012. 849 p.

2. Manohar V., Rahmat-Samii Y. Understanding the radiation characteristics of metal-only, low-profile, offset stepped parabolic reflector antennas: simulation, analysis, and measurement. IEEE Transactions on Antennas and Propagation. 2021. Vol. 69. No. 8. P. 5078-5083. https://doi.org/10.1109/TAP.2021.3060090.

3. Garcia E. et. al. Analizing large reflectors antennas built with complex knitted meshes. IEEE Int. Symp. on Antennas and Propagation (APSURSI). 2011. P. 934-937. https://doi.org/10.1109/APS.2011.5996430.

4. Oguzer T., Altintas A., Nosich A. I. Focusing of THz waves with a microsize parabolic reflector made of graphene in the free space. J. Eur. Opt. Soc.-Rapid Publ. Vol. 13. No. 16. https://doi.org/10.1186/s41476-017-0041-0.

5. Richmond J. H. Scattering by an arbitrary array of parallel wires. IEEE Trans. Microwave Theory and Techniques. 1965. Vol. 13. No. 4. P. 408-412.

6. Yin L. et al. Subwavelength focusing and guiding of surface plasmons. Nanoletters. 2005. Vol. 5. No. 7. P. 1399-1402. https://doi.org/10.1021/n1050723m.

7. Krenn J. R. et al. Surface plasmon micro- and nano-optics. J. of Microscopy. 2003. Vol. 209. No. 3. P. 167-172.

8. Natarov D. M., Marciniak M., Sauleau R. Modeling of discrete parabolic reflector made of sub-wavelength plasmonic wires. Proc. Int. Symp. MSMW-13, Kharkiv. 2013. P. 455-457.

9. Natarov D. M. et al. Effect of periodicity in the resonant scattering of light by finite sparse configurations of many silver nanowires. Plasmonics. 2014. Vol. 9. No. 2. P. 389-407. https://doi.org/10.1007/s11468-013-9636-5.

10. Kottman J. P., Martin O. J. F. Plasmon resonances of silver nanowires with a nonregular cross-section. Phys. Rev. B. 2001. Vol. 64, P. 235402-10. https://doi.org/10.1103/PhysRevB.64.235402.

11. Natarov D. M. et al. Periodicity-induced effects in the scattering and absorption of light by infinite and finite gratings of circular silver nanowires. Optics Express. 2011. Vol. 19. No. 22. P. 22176-22190. https://doi.org/10.1364/OE.19.022176.

12. Bulygin V. S., Nosich A. I., Gandel Y. V. Nystrom-type method in three-dimensional electromagnetic diffraction by a finite PEC rotationally symmetric surface. IEEE Trans. Antennas and Propagation. 2012. Vol. 60. No 10. P. $4710-4718$. https://doi.org/10.1109/TAP.2012.2209194.

13. Scott C. Modern methods of reflector antenna analysis and design. 1990. Boston : Artech House Boston, 144 p. 


\section{Відомості про авторів:}

Натаров Денис Михайлович кандидат фізико-математичних наук науковий співробітник Інституту радіофізики та електроніки ім. О.Я. Усикова НАН України, Харків, Україна https://orcid.org/0000-0003-4170-9211

\section{Натарова Анастасія Олегівна}

кандидат фізико-математичних наук доцент Харківського національного університету Повітряних Сил ім. І. Кожедуба,

Харків, Україна

https://orcid.org/0000-0002-0856-3356

\section{Кокодій Микола Григорович}

доктор фізико-математичних наук професор професор Харківського національного університету ім. В.Н. Каразіна, Харків, Україна https://orcid.org/0000-0003-1325-4563
Information about the authors:

\section{Denis Natarov}

Candidate of Physics and Mathematics

Research Associate of O.Y. Usikov Institute

for Radiophysics and Electronics NASU,

Kharkiv, Ukraine

https://orcid.org/0000-0003-4170-9211

\author{
Anastasia Natarova \\ Candidate of Physics and Mathematics \\ Senior Lecturer of Ivan Kozhedub Kharkiv \\ National Air Force University, \\ Kharkiv, Ukraine \\ https://orcid.org/0000-0002-0856-3356
}

\section{Mukola Kokodii}

Doctor of Physics and Mathematics Professor

Professor of V.N. Karazin

Kharkiv National University

Kharkiv, Ukraine

https://orcid.org/0000-0003-1325-4563

\title{
ФОКУСИРОВКА ЭЛЕКТРОМАГНИТНЫХ ВОЛН ДИСКРЕТНЫМ ПАРАБОЛИЧЕСКИМ РЕФЛЕКТОРОМ ИЗ ДИЭЛЕКТРИЧЕСКИХ НИТЕЙ
}

\author{
Д.М. Натаров, А.О. Натарова, Н.Г. Кокодий
}

Рассмотрена проблема рассеяния плоских волн дискретным параболическим рефлектором (ДПР), изготовленным из равноудаленно расположенных кремниевых нитей. Исследована фокусирующая способность таких отражателей как в случае Е, так и Н-поляризации. Для моделирования этой задачи использован метод частичного разделения переменных вместе с регуляризачией, что приводит к матричному уравнению Фредгольма второго рода для коэффициентов разложения функиии поля. Это гарантирует сходимость решения и позволяет получить численные результать любой заданной точности. Численно изучены характеристики отражения таких ДПР, а также их фокусирующая способность, картины ближнего поля, значения функиии поля в фокальном пятне.

Ключевые слова: ичилинд, дискретный параболический рефлектор, фокусировка, ближнее поле, отражсательная способность.

\section{FOCUSING OF ELECTROMAGNETIC WAVES BY DISCRETE PARABOLIC REFLECTOR MADE OF DIELECTRIC WIRES}

D. Natarov, A. Natarova, M. Kokodii

We consider a problem of the plane wave scattering by a discrete parabolic reflector (DPR) made of silicon wires. We model DPR as a finite collection of parallel identical wires, which centers are symmetrically located on the parabolic curve. The wires are assumed to be infinite circular cylinders with real-value relative dielectric permittivity, i.e. we neglect its dispersion and losses, therefore one can investigate problem in a wide range of relative frequency values. For modeling of this problem we use the method of partial separation of variables together with regularization. The full-wave numerical solution can be obtained by expanding the field functions in terms of the azimuth exponents in the local polar coordinates, using addition theorems for cylindrical functions, and applying the boundary conditions on the surface of each wire. This leads to the block-type Fredholm second kind matrix equation for the field expansion coefficients. This fact guarantees convergence of solution and predicted accuracy of our calculations. We use total scattering cross-section per wire and reflectivity per period frequency dependences to investigate scattering properties of such DPRs. To investigate a focusing ability we use frequency dependences of the maximum absolute value of the E and H field for E- and H-polarization cases, respectively, in the focal spot of the DPRs together with near-field patterns. We investigate DPRs made of high-refractive-index, silicon, wires which, together with optimal focus-toaperture rate 0.25 should provide better focusing abilities. Using TSCS, reflectivity, field-in-focus frequency dependences of investigated DPRs we demonstrate that denser DPRs made of sub-wavelength wires (lower p/a ratio) reflect and focus not better than sparse ones. Besides, we demonstrate that DPRs made of sub-wavelength wires have the best reflective and focusing abilities. However the effect of periodicity, which leads to high reflection of the incident wave for linear gratings, for DPRs is destroyed by curvature of the parabola and has no effect on reflecting and focusing characteristics.

Keywords: wire, discrete parabolic reflector, focusing, nearfield, reflectivity. 